\title{
VIVÊNCIAS ACADÊMICAS E SOFRIMENTO PSÍQUICO EM ESTUDANTES DE MEDICINA
}

Academic experiences and psychic suffering in medical students

Vie académique et souffrance psychique chez les étudiants en médecine

Vivencias académicas y sufrimiento psíquico en estudiantes de medicina

Rafaela Cruz de Oliveira ${ }^{1}$

ORCID: http://orcid.org/0000-0001-6335-0292

Universidade do Estado do Amazonas, Manaus, Amazonas, Brasil. Acadêmica de Medicina da Universidade do Estado do Amazonas (UEA).

Socorro de Fátima Moraes Nina ${ }^{2}$

ORCID: http://orcid.org/0000-0001-5684-9722

Universidade do Estado do Amazonas, Manaus, Amazonas, Brasil

Professora Adjunta da Universidade do Estado do Amazonas (UEA). Doutora em Sociedade e Cultura na Amazônia - UFAM. Membro do GT Psicodinâmica e Clínica do Trabalho da Associação Nacional de Pesquisa e LAPSIC-AM. Psicóloga do CEREST-AM.

\section{Resumo}

Estudar Medicina acompanha cobranças pessoais e sociais, pois é uma profissão de grande responsabilidade. O curso possui carga horária elevada e exige dedicação, esforço e sacrifício de seus alunos, que muitas vezes precisam abdicar de atividades de lazer e criar novos hábitos de estudo. Portanto, objetiva-se descrever os problemas físicos, psicológicos e sociais identificados como causados pela vida acadêmica como estudante de Medicina. A pesquisa foi realizada com 36 estudantes de todos os períodos do curso, selecionados de forma aleatória. Utilizou-se o Protocolo de Avaliação dos Riscos Psicossociais no Trabalho - PROART, além de entrevista semiestruturada. Os resultados evidenciaram sintomas psicológicos, como o mau-humor e vontade de ficar sozinho, e sintomas físicos, como dor de cabeça e nas costas. Além disso, os acadêmicos afirmaram haver necessidade de mudança na grade curricular e demonstraram sofrerem com a falta de tempo e a ansiedade frente às pressões cotidianas. Conclui-se que o curso de Medicina, com sua carga horária extenuante e por exigir dedicação em tempo integral, pode expor os alunos a situações exaustivas e de sofrimento, mostrando a importância de refletir sobre a forma que eles lidam com sua formação e pensar em estratégias para atenuar as vivências que podem levar ao sofrimento.

Palavras-chave: Saúde Mental; Centros Médicos Universitários; Medicina.

\section{Abstract}

Studying Medicine accompanies personal and social charges, as it is a profession of great responsibility. The course has a high workload and requires dedication, effort and sacrifice from its students, who often need to give up leisure activities and create new study habits. It aims to describe the physical, psychological and social problems identified as caused by academic life as a medical student. The research was conducted with 36 students from all periods of the course, randomly selected. The Protocol for the Evaluation of Occupational Psychosocial Risks PROART, in addition to a semi-structured interview, was used. The results showed psychological symptoms, such as moodiness and willingness to be alone, and physical symptoms such as headaches and backaches. In addition,

\footnotetext{
${ }^{1}$ rcdo.med16@uea.edu.br
}

2 snina@uea.edu.br 
academics have stated that there is a need for change in the curriculum and have been shown to suffer from lack of time and anxiety in the face of daily pressures. It is concluded that the Medicine course, with its strenuous workload and for requiring full-time dedication, can expose students to exhaustive situations and suffering, showing the importance of reflecting on the way they deal with their formation and think about strategies to mitigate the experiences of suffering.

Keywords: Mental Health; Academic Medical Centers; Medicine.

\section{Résumé}

Étudier la Médecine s'accompagne de charges personelles et sociales. C'est pourquoi c'est une occupation avec beaucoup de responsabilités. Les cours sont importants et necessite la dévotion, l'effort et le sacrifice des étudiants, qui souvent doivent reduire les loisirs et créer des nouvelles habitudes. Par conséquent, l'objectif est de décrire les problèmes physiques, psychologiques et sociaux identifiés comme étant causés par la vie universitaire en tant qu'étudiant en médecine. La recherche était effectuée avec 36 étudiants de toutes les périodes du cours, choisis au hasard. Il a été utilisé « Le Protocole de Mesures des Risques Psychosociaux au Travail », en plus de entretien semi-structuré. Les résultats ont prouvé des symptômes psychologiques, comme la mauvaise humeur et le désir d'être seul. Et pour les symptômes physiques : mal de la tête et dos. En outre, les étudiants ont affirmé qu'il était nécessaire de changer le programme et ils souffrent d'anxiété à propos des pressions quotidiennes. Donc, les cours de médecine, avec leur charge de travail, d'exigence et de dévouement total, peuvent exposer les étudiants à des situations extrêmes de souffrance, montrant l'importance de réfléchir à la façon dont ils gèrent leur formation et penser aux stratégies pour atténuer des situations qui peuvent les faire souffrir.

Mots clés: Santé mentale; Centres médicaux universitaires; Médecine.

\section{Resumen}

Estudiar Medicina acompaña cobranzas personales y sociales, pues es una profesión de gran responsabilidad. El curso tiene carga horaria elevada y exige dedicación y sacrificio de sus alumnos, que muchas veces necesitan abdicar de actividades de ocio y crear nuevos hábitos de estudio. Por lo tanto, se objetiva describir los problemas físicos, psicológicos y sociales identificados como causados por la vida como estudiante de Medicina. La encuesta fue realizada con 36 estudiantes de todos los períodos del curso, seleccionados de forma aleatoria. Se utilizó el Protocolo de Evaluación de los Riesgos Psicosociales en el Trabajo - PROART, además de entrevista semiestructurada. Los resultados evidenciaron mal humor y voluntad de quedarse solo como síntomas psicológicos, y dolor de cabeza y de espalda como síntomas físicos. Los académicos afirmaron haber necesidad de cambio en el plan de estudios y demostraron sufrir con falta de tiempo y ansiedad frente a las presiones cotidianas. Se concluye que el curso de Medicina, con su carga horaria extenuante y por exigir dedicación integral, puede exponer a los alumnos a situaciones exhaustivas y de sufrimiento, mostrando la importancia de reflejar sobre la forma que ellos viven su formación y pensar en estrategias para atenuar las vivencias que pueden llevar al sufrimiento.

Palabras clave: Salud Mental; Centros Médicos Académicos; Medicina.

INTRODUÇÃO

A formação em Medicina é densa onde os alunos convivem com uma realidade que reflete momentos de felicidade e prazer assim como momentos de ansiedade e sofrimento, uma vez que ao conquistar o grande sonho de cursar medicina, se depararam com a pratica de lidar com vida e morte, ambiente competitivo, privação de lazer e sensação de insegurança técnica, que segundo Andrade et.al (2014) em estudos com universitários do Ceará, estas questões funcionam como um retrato da formação, tais processos podem interferir no sofrimento 
psíquico do discente. Corroborando com a temática, Benevides-pereira \& Gonçalves (2009) afirmam que o curso de medicina é popularmente conhecido como um dos mais difíceis e trabalhosos por exigir muita dedicação, esforço e sacrifício dos alunos, além de resistência física e mental. Para Bellodi \& Martins (2014) “o ingresso em um curso de graduação em Medicina significa não apenas a concretização de um sonho, repleto de expectativas e idealizações, como também a recompensa de um esforço e uma nova etapa de vida" (p. 15).

\section{Sofrimento psíquico e vida acadêmica}

Estudos apontam que o acadêmico de medicina passa por uma fase da euforia ao ingressar na universidade, pois ganha-se novo status na hierarquia familiar, sente-se socialmente mais valorizado e imagina que seus problemas terminaram. Porém, em seguida pode acontecer uma fase de desencanto, onde começa a perceber com o que realmente terá que lidar durantes esses anos de estudos, como carga horária excessiva, grande densidade de conteúdo para estudar (Millan,1999).

O autor também ressalta que um outro aspecto que causa angústia nesta fase é o seu próprio desempenho. Tem-se os resultados das primeiras provas e alunos que até então alcançavam as melhores notas no ensino médio, passam a ter notas mais baixas, que não correspondem ao seu padrão anterior e às suas expectativas. Segundo Benevides-Pereira \& Gonçalves (2009), muitos não têm condições de enfrentar essas situações de estresse, seja por características pessoais, falta de preparo ou por motivos e situações diversas, inclusive inerentes ao próprio curso, levando ao sofrimento psíquico. De acordo com Fiorotti (2010):

Os fatores de estresse, presentes na graduação médica, incluem competição no processo de seleção, sobrecarga de conhecimentos, dificuldade na administração do tempo entre um grande número de atividades e pouco tempo para atividades de lazer, individualismo, responsabilidade e expectativas sociais do papel do médico. Outros fatores incluem o contato com a morte e inúmeros processos patológicos, o exame físico em um paciente, o medo de adquirir doenças, o medo de cometer erros e sentimentos de impotência diante de certas doenças. [...] (p. 18)

O conteúdo a ser aprendido é extenso e o número de disciplinas e de professores também, gerando grande quantidade de atividades avaliativas. Esse processo pode causar sobrecarga emocional, estresse e queda no rendimento (Pereira, 2014). E ainda há alunos que vêm de outras cidades e precisam, além de se adaptar ao ambiente universitário, lidar com responsabilidades que não tinham antes, como cuidados com a casa, alimentação e pagamento de contas (Millan, 1999). 
Outra fonte constante de sofrimento é a competição entre os próprios alunos, levando à busca exagerada do "currículo paralelo", que é o excesso de ligas acadêmicas, congressos, monitorias, tudo que possa melhorar o currículo e proporcionar maiores chances de aprovação na residência médica. Da mesma forma, as expectativas dos acadêmicos costumam ser um problema. Uma autocobrança exagerada em ser um bom aluno, ter boas notas, faz com que não tolerem muito a frustração, aumentando seu sofrimento psíquico (Pereira, 2014).

Andrade (2014) constatou que o período de maior sofrimento psíquico vivenciados pelos estudantes corresponde àquele em que entram em contato com pacientes gravemente enfermos. A partir do quarto semestre, os alunos começam a ter contato com a realidade clínica, que pode constituir um fator de sofrimento, pois o estudante sente medo e insegurança de não ser capaz de lidar com os pacientes.

Já no internato, o estudante vive a profissão médica de uma forma mais realista, assumindo maiores responsabilidades com os pacientes, uma vez que já pode intervir e opinar em condutas, bem como realizar certos procedimentos sob orientação de seus preceptores. Estudos evidenciam que todas essas mudanças advindas da última etapa do curso podem motivar o sofrimento psíquico entre os acadêmicos (Costa, 2011).

Segundo Ribeiro et al. (2015), sofrimento psíquico é percebido como a apresentação de questões subjetivas que causam desconforto emocional; mal-estar psíquico; insatisfação e tristeza persistentes; desmotivação; desesperança e dificuldades emocionais em lidar com o cotidiano da vida.

Ao referenciar Dejours quando o autor discorre sobre sofrimento no ambiente de trabalho, pode-se analisar sua teoria e ideias considerando o estudante como um "trabalhador" cujo ambiente de trabalho seria a universidade.

Para Dejours, a noção de sofrimento é central e implica um estado de luta do sujeito contra as forças que estão empurrando em direção à doença mental. Sendo a universidade a organização do trabalho em que o estudante está inserido pode configurar-se "como o espaço de luta que ocorre no campo situado entre, de um lado, o bem-estar, e, de outro, a doença mental ou a loucura" (Dejours, 1993, 2007).

Afinal, ao interligar o processo de estudo e as relações sociais na academia o estudar pode ser visto como um trabalhar, de forma que, recorre-se a Anchieta (2011), quando conceitua trabalho como uma atividade que exerce papel importante na construção da subjetividade humana, uma vez que organiza e estrutura a vida daquela pessoa, lhe dá uma identidade, cria uma rede de relações e lhe dá direitos e obrigações. Dessa forma, é um ponto significativo no que diz respeito à saúde mental não só individual, como também coletiva. 
O trabalhador inserido numa determinada organização de trabalho desenvolve uma carga psíquica resultante das excitações exógenas e endógenas pelas quais é submetido constantemente, estas são acumuladas, retidas culminando na chamada tensão psíquica. Essa energia acumulada precisa de uma via de descarga para ser canalizada de maneira apropriada, sendo que esta deveria ser encontrada na própria instituição de trabalho ou, no caso do estudante, na universidade, afim de assegurar um equilíbrio, rebaixando a tensão e consequentemente diminuindo a carga psíquica. Mas o que se nota na organização do trabalho é o oposto, tornando o trabalho fatigante por não oferecer a via de descarga necessária (Milanesi, 2008; Dejours,2009).

Para Dejours (2009) a fadiga é uma testemunha não específica da sobrecarga que pesa sobre um ou outro dos setores do organismo psíquico e somático. O trabalhador torna-se cansado tanto física quanto psicologicamente, pois sua relação com o conteúdo significativo do trabalho não é satisfatória, seus desejos e motivação são bloqueados, e fica então condicionado apenas ao comportamento produtivo. Tal afirmação, propicia refletir sobre algumas vivências acadêmicas, descritas por autores que pesquisam essa temática, a vivência depressiva alimentase da sensação de adormecimento intelectual, de anquilose mental, de paralisia da: imaginação e marca o triunfo do condicionamento ao comportamento produtivo (Dejours, 1992, 1999, 2009).

\section{Lidando com o sofrimento}

O indivíduo exposto a pressões que levam ao sofrimento psíquico acabam exteriorizando-o de alguma forma, sendo que a maneira como isso ocorre se manifesta por meio de comportamentos próprios de cada indivíduo, pois cada um reage de maneira particular a cada situação dependendo da sua personalidade (Milanesi, 2008).

As vivências de sofrimento desencadeadas por uma organização, rígida podem levar ao adoecimento, transformando-se em sofrimento patógeno uma vez que dificulta que o sujeito procure formas de enfrenta-lo e/ou superá-lo. Porém quando esses comportamentos conseguem transformar as vivências de sofrimento em vivências de prazer, chama-se de mobilização subjetiva ou coletiva, sendo transformado em vivência de prazer, é considerado sofrimento criativo, visto que possibilitou ao sujeito encontrar meios de não sucumbir à doença (Moraes, 2013). Mas, quando isso não acontece, e as estratégias apenas protegem o ego permanecendo o sofrimento, chama-se de estratégias defensivas (Anchieta, 2011). 
Como estratégia defensiva, para tentar contornar ou camuflar o sofrimento, pode-se identificar conflitos interpessoais, com condutas e atitudes que podem ser agressivas, comportamentos violentes ou atitudes passivas, como apenas deixar de tomar iniciativas e assumir responsabilidades.

Na academia observa-se que é possível que o aluno se feche, comece a não se comunicar com os outros, preocupando-se somente consigo e mostrando até características paranoicas, desconfiando dos colegas, que poderiam estar tentando prejudicá-lo de alguma maneira. Essa falta de confiança e companheirismo entre os colegas gera conflitos e tensões, assim o relacionamento termina sendo rompido para evitar conflitos (Dejours, 1994).

A atitude de se ocupar com inúmeras atividades também mostrou-se uma forma negativa de lidar com o sofrimento e, mesmo assim, é usada na sociedade atual. Significa que quando se mantém ocupado com vários compromissos, não se tem tempo para olhar para a própria dor, então não se sofre. Mas o sofrimento não deixa de existir por ser negado, ele apenas não é identificado. Uma consequência disso pode ser a somatização, que é o próprio corpo manifestando fisicamente essa dor emocional, que pode ser através de uma dor de cabeça, dor muscular ou distúrbios gastrintestinais (Pereira, 2014).

Por outro lado, Zonta (2006) encontrou em seu estudo formas de mobilização subjetiva realizadas por alguns estudantes para enfrentar a dor e o sofrimento de maneira positiva. São elas: o autocuidado através do resgate de hábitos de vida saudáveis como ter uma boa alimentação, realizar exercícios físicos e atividades de lazer; bem como a religiosidade e a valorização dos relacionamentos interpessoais, através do contato com familiares e amigos. Esta uma maneira de ressignificar a dor, entrando em contato com sua subjetividade e utilizando conhecimentos práticos e coletivos para transformar as situações causadoras de sofrimento em alguma forma de prazer (Mendes, 2007).

Quando já foram usados todos os mecanismos possíveis e as pressões continuaram, o sofrimento torna-se patogênico, pois leva ao desiquilíbrio psíquico e à descompensação e, consequentemente, à doença (Milanesi, 2008).

As informações expostas mostram a importância de conhecer a realidade desses alunos, identificar quais seus problemas psicossociais e a forma como lidam com eles. Essas informações poderão contribuir para mudanças na organização do ambiente acadêmico.

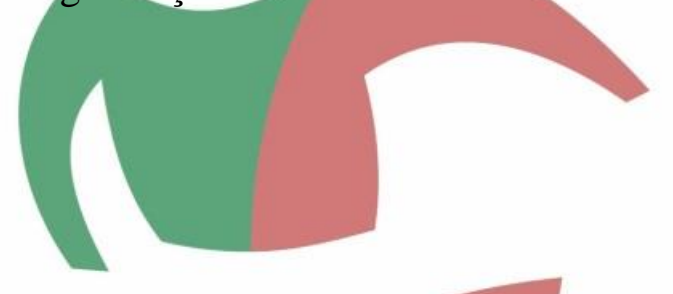




\section{MÉTODOS}

Trata-se de uma pesquisa social com caráter exploratório e descritivo. A pesquisa social é uma modalidade que busca conhecer e compreender a realidade da população estudada para que se possam buscar soluções para seus problemas cotidianos (Dyniewicz, 2009).

Foram empregados métodos qualitativos e quantitativos, objetivando complementaridade na tentativa de buscar uma visão mais abrangente da vivência compartilhada pelos estudantes de Medicina. O método quantitativo se fez imprescindível para descrição do objeto e coleta de dados do inventário, enquanto o método qualitativo foi necessário para do conhecimento das especificidades subjetivas dos participantes, possibilitando conhecer a magnitude dos fatos estudados (Dyniewicz, 2009, p. 107)

Em relação à etapa quantitativa do estudo, foi descritiva classifica-se como estudo de corte transversal empregado com o intuito de mensurar os sintomas físicos e psicológicos percebidos como fatores de risco para os acadêmicos, por meio de um questionário desenvolvido para tal finalidade. A abordagem qualitativa foi constituída de perguntas abertas, proporcionando aos estudantes a oportunidade de expressar suas principais dificuldades e suas formas de lidar com elas.

O estudo foi desenvolvido na Escola Superior de Ciências da Saúde (ESA), unidade da Universidade do Estado do Amazonas (UEA), localizada em Manaus, Amazonas. Os critérios de inclusão foram apenas ser estudante de Medicina da UEA, maior de 18 anos e aceitar participar voluntariamente da pesquisa.

A população de análise corresponde ao total de 876 alunos do curso de Medicina da Universidade do Estado do Amazonas. O curso possui doze períodos, que são divididos em três ciclos, sendo o Ciclo Básico composto do $1^{\circ}$ ao $4^{\circ}$ período, o Ciclo Clínico do $5^{\circ}$ ao $8^{\circ}$ período e o Internato do $9^{\circ}$ ao $12^{\circ}$ período. Dentro de cada período foram escolhidos três participantes de forma voluntária e aleatória, utilizando critérios de acessibilidade e disponibilidade, compondo uma amostra 36 participantes.

Como instrumento para coleta de dados foi utilizada a Escala de Danos Físicos e Psicossociais no Trabalho (EDT), que compõe o Protocolo de Avaliação dos Riscos Psicossociais no Trabalho - PROART, e é composta por três fatores, o primeiro os danos psicológicos, os danos sociais, e por fim os dados físicos.

"O primeiro fator é danos psicológicos, definidos como sentimentos negativos em relação a si mesma e à vida em geral. $\mathrm{O}$ segundo fator é danos sociais, definidos como isolamento e dificuldades nas relações familiares e sociais. O terceiro fator é danos 
físicos, que diz respeito a dores no corpo e distúrbios biológicos [...]” (Facas, 2013, p. 131).

As questões abertas aplicadas foram as sugeridas por Facas (2013) na utilização do Protocolo de Avaliação dos Riscos Psicossociais do Trabalho (PROART). Têm como objetivo analisar a subjetividade de cada participante, uma vez que o sofrimento é multifatorial e carrega consigo a delicadeza da subjetividade, singular para cada estudante (Ribeiro, 2015).

Os dados qualitativos foram interpretados pela Análise dos Núcleos de Sentidos (ANS) de Ana Magnólia Mendes, técnica adaptada a partir da técnica de análise de conteúdo categorial desenvolvida por Bardin. A ANS consiste no desmembramento do texto em grupos, com base em temas constituídos de um núcleo de sentido, ou seja, que tratam de temas similares (Mendes, 2007).

Já a análise dos dados quantitativos foi realizada por meio de estatística descritiva, com a utilização do pacote estatístico SPSS (Statistical Package for Social Science).

A pesquisa foi aprovada pelo Comitê de Ética em Pesquisa da Universidade do Estado do Amazonas (CEP/UEA) sob a seguinte numeração: CAEE 79439717.8.0000.5016.

\section{RESULTADOS}

A partir da aplicação dos questionários, foi possível identificar diversas características de sofrimento psíquico entre os estudantes de Medicina de todos os períodos da universidade. Alguns pontos tiveram destaque na pesquisa:

O mau-humor (gráfico 1) foi o fator de maior prevalência entre os estudantes, uma vez que apenas um aluno entre 36 afirmou nunca apresentar essa característica, enquanto $36 \%$ disseram apresentarem frequentemente e $11 \%$, sempre. Isto pode ser decorrente do fato dos estudantes não terem tempo de realizar atividades necessárias para o seu bem-estar, como ter uma noite adequada de sono ou momentos de lazer. Assim como Andrade, et al. (2014) afirma que a carga horária extenuante, em turno integral, além da necessidade de novos hábitos de estudo, parece ter provocado um modelo em que o aluno precisaria se privar de atividades de lazer e parar de realizar atividades físicas, que são fatores relevantes para a presença de mau humor. 
Gráfico 1: Incidência de mau-humor nos participantes da pesquisa

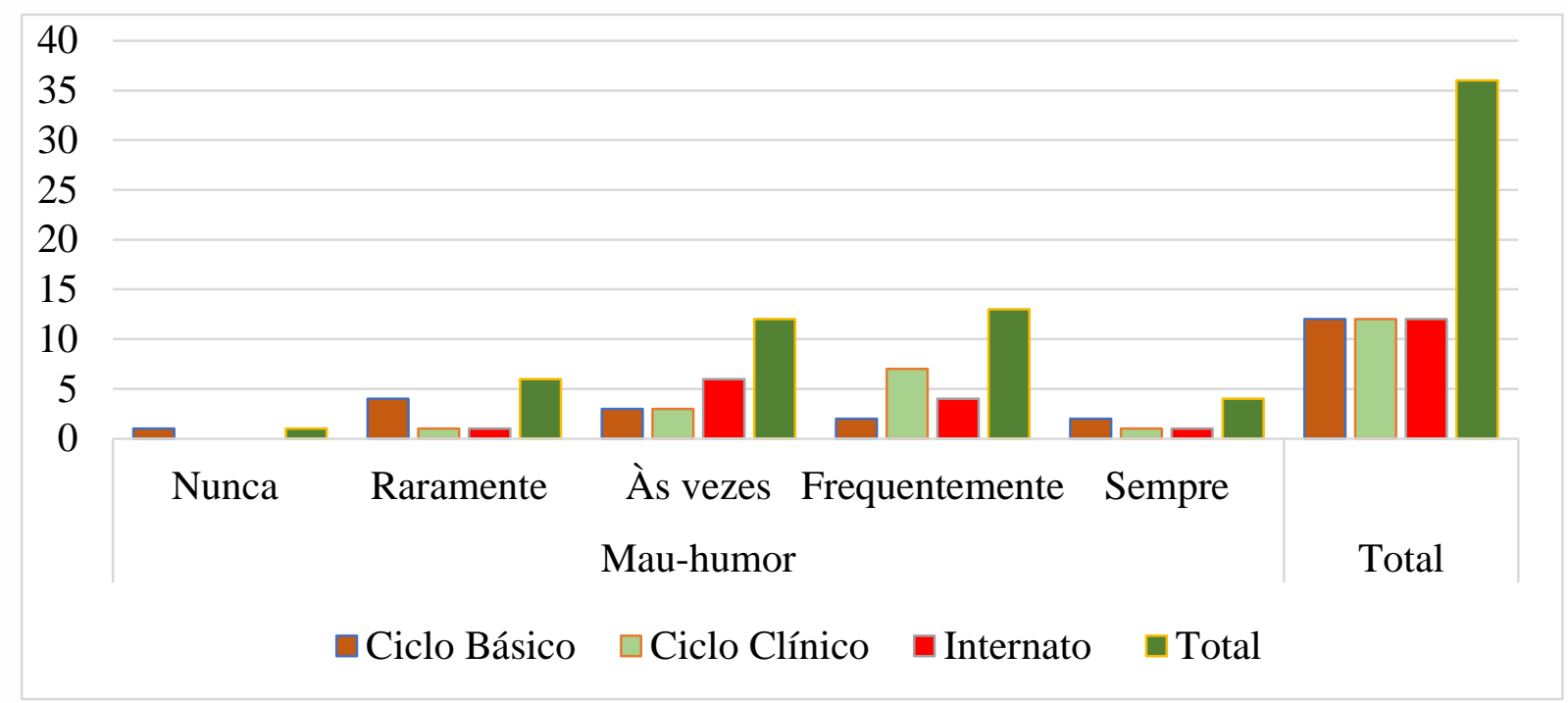

Fonte: Autores

Entre problemas psicossociais, observou-se que 58,3\% dos participantes da pesquisa afirmam sentirem-se tristes com alguma frequência (gráfico 2), bem como 15,9\% disseram terem problemas com a família às vezes. Da mesma maneira, Ribeiro (2014) afirma que vários estudantes procuram atendimento espontaneamente ou encaminhados por seus professores ou colegas, com sintomas de angústia, ansiedade, tristeza. Os motivos são muito variados, mas há uma recorrência em dificuldades vivenciadas com a família, desentendimentos, falta de apoio ou cobrança para bons resultados.

Gráfico 2: Incidência de tristeza nos participantes

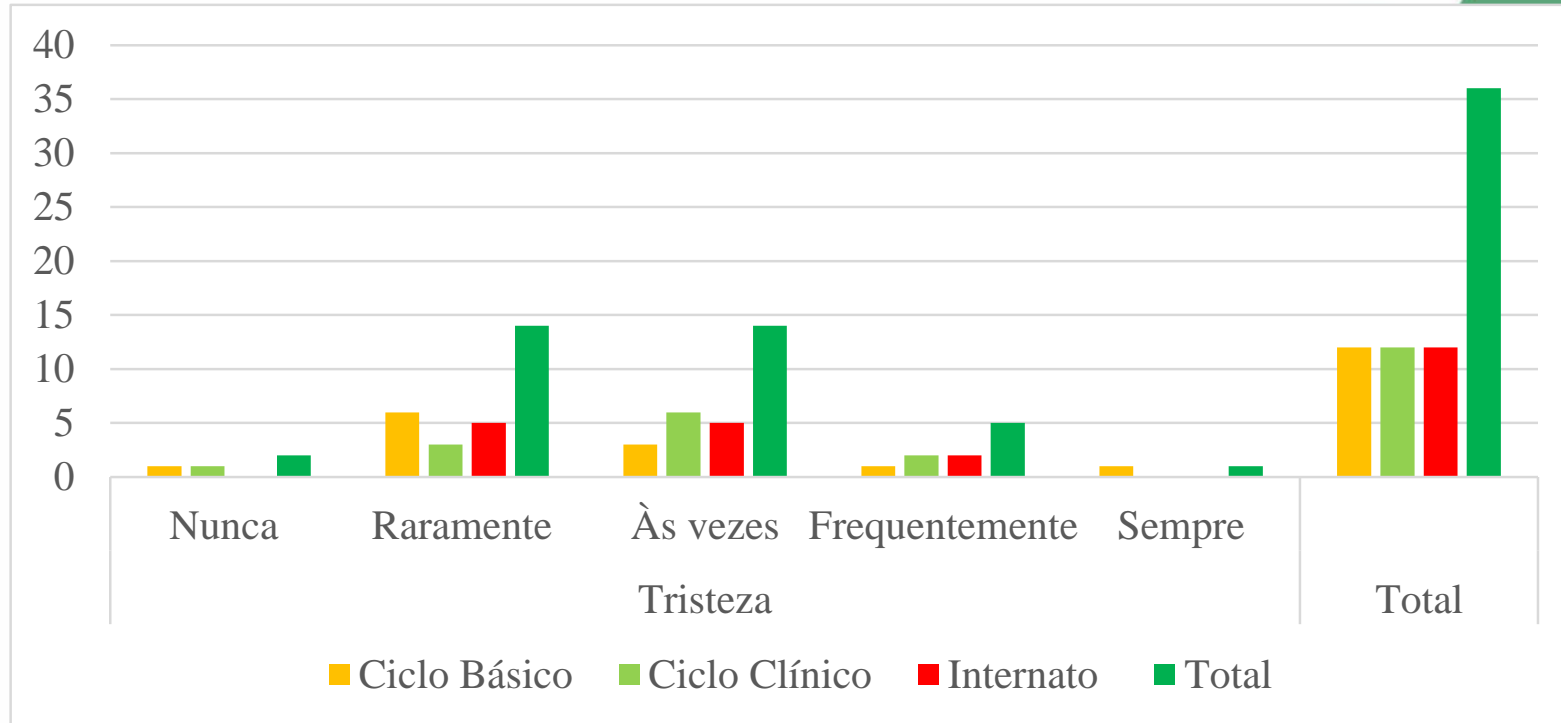

Fonte: Autores 
Também foram identificados problemas físicos nos participantes da pesquisa, já que 26 alunos do total de 36 afirmam sofrerem de dor de cabeça, sendo que 19,4\% dizem terem sempre, $30,5 \%$ frequentemente e 22,2\% às vezes. Quanto a problemas no estômago, 16 dos 36 participantes afirmam possuírem, sendo que 8,3\% afirmam sofrerem sempre deste problema, $8,3 \%$ afirmaram que frequentemente e $27,8 \%$ às vezes. Ainda neste estudo, 28 dos 36 participantes disseram sofrer de alterações do sono, sendo que 16,6\% afirmam terem sempre, $38,8 \%$ frequentemente e 22,2\% às vezes. Os estudos de Girardi \& Borges (2017) com acadêmicos estrangeiros de Florianópolis mostram a mesma realidade, uma vez que todos os participantes da pesquisa possuíam pelo menos um exemplo de sintoma físico constante em seu cotidiano, sendo os principais: dores de cabeça, problemas no estômago, cansaço, alterações no sono, entre outros.

Já no momento da entrevista foi possível conhecer a realidade dos estudantes de uma forma mais subjetiva e personalizada. Ao fazer perguntas aos estudantes e observar o ambiente e o estado em que se encontravam-se, foi possível observar algumas questões não encontradas nos questionários.

Uma questão que se repete em todos os períodos é a da falta de tempo por conta da grande carga horário do curso. Podemos observar nas seguintes respostas dos alunos quando questionados sobre suas dificuldades na universidade: A7 "Tenho dificuldade de realizar outras atividades além das acadêmicas"; A12 "Excessiva carga horária, que impossibilita muitas vezes a conciliação com a vida social.”; A17 “Conciliar o tempo dos estudos com outras atividades, assim como manter uma vida saudável.”; A36: “A disponibilidade de tempo, passar o dia todo na faculdade é muito cansativo e ainda tem que chegar em casa e resolver milhões de outras coisas.”. Inclusive Pereira (2014) afirma que a sobrecarga inerente à formação médica, com carga horária excessiva e muito conteúdo a ser aprendido foram alguns dos estressores entre os alunos que participaram de sua pesquisa.

Igualmente, permanece durante todos os períodos a necessidade de reformulação da grade curricular do curso de Medicina para que os alunos consigam melhor desempenho. Essa questão foi apontada nas seguintes respostas quando os alunos foram abordados sobre o que poderia ser feito para melhorar a vida acadêmica: A2 "Reduzir a carga horária de forma que os conteúdos fiquem menos enfadonhos"; A8 "Melhorar a organização dos horários (principalmente do internato), evitar sobrecarga de horários e atividades, cumprir planos de ensino"; A12 "Reprogramar os horários tanto da graduação como do internato"; A15 "Menor carga horária presencial para ter mais tempo livre para estudar em casa." Assim como na pesquisa de Andrade 
(2014), onde 92\% dos estudantes apontaram a carga horária como desfavorável e 92,3\% afirmaram que a grade curricular poderia ser melhor organizada.

Fiorotti (2010) também encontraram em sua pesquisa que $84,3 \%$ dos alunos dizem não praticar atividades de lazer na frequência desejada e 85,2\% não praticam qualquer tipo de esporte. Da mesma forma, os alunos afirmam não terem tempo suficiente nem para estudar o conteúdo necessário, como vemos nas seguintes falas: A31: "A falta de tempo para estudar e a quantidade de matéria.”; A43: “[...] acabo não dormindo algumas noites para poder dar conta dos assuntos. [...]"; A37: "Falta de tempo para estudar e cuidar da minha saúde. Falta de tempo para lazer. [...]".

No Internato observou-se uma pressão maior quanto a ser um bom aluno, pelo fato de que já estão concluindo o curso e logo estarão no mercado de trabalho, tendo que lidar com responsabilidades maiores. Essa questão foi levantada pelos seguintes alunos quando lhes foi perguntado qual o maior problema relacionado ao curso: A12: "Pressão exacerbada do superior das atividades do internato"; A10: "As principais dificuldades estão relacionadas às relações interpessoais no internato e a constante cobrança em ser 'boa'”. Andrade (2014) também diz que o ambiente do internato como um processo de avaliação constante e formativo da imagem como futuro médico, o temor de não ser um bom médico e o convívio acumulativo com o sofrimento dos pacientes, além da rotina mais extenuante é um processo que requer atenção.

Uma das estratégias de enfrentamento do sofrimento apontadas por Freud é a submissão às normas e regras do trabalho, bem como o isolamento voluntário (Macêdo, 2015). Este tipo de estratégia envolve não lutar por melhores condições de trabalho (ou, no caso, de estudo e conforto dentro da universidade) e somente fazer sua obrigação aceitando as condições onde se encontra. Observa-se essa atitude em alguns alunos do Internato quando questionados sobre o que fazem para lidar com seu sofrimento: A11: "Fazendo o meu serviço e não se importando com os outros"; A14: "Abstraindo, dificilmente tento resolver"; A9: "Vou vivendo"; A1: "Aguento". Da mesma forma, Pereira (2014) encontrou que 55,3\% dos participantes de sua pesquisa apontam reações de negação e fuga como sua forma de lidar com a dor ou o sofrimento vindo das atitudes acadêmicas.

Já no Ciclo Clínico, pode-se perceber a estratégia de enfrentamento chamada Sublimação, onde o indivíduo usa sua angústia para produzir algo positivo. Encontra-se essa característica nas seguintes respostas de quando perguntou-se as alunos qual o seu maior prazer em ser estudante de Medicina: A20: "Falar com os pacientes (quando eles estão entediados e veem na nossa companhia uma coisa boa)."; A37: "A possibilidade de ajudar as pessoas a cuidarem de seu bem mais precioso, sua saúde. O obrigado de um paciente completa o dia.”; 
A33: "Aprender mais e poder usar desse conhecimento para ajudar outras pessoas [...]"; A36: "Poder ajudar as pessoas com o nosso conhecimento."

\section{DISCUSSÃO}

Este estudo identificou situações exaustivas e de sofrimento relacionadas ao curso de Medicina, como a falta de tempo para organizarem seus estudos e para atividades de lazer, a grande quantidade de provas e outras atividades avaliativas, a dificuldade do conteúdo, o sono e o cansaço excessivos. Estas informações merecem ser analisadas para que possam-se pensar em mudanças afim de melhorar a vivência em ambiente acadêmico, uma vez que todos os participantes da pesquisa apresentaram algum sintoma físico e/ou psicológico de sofrimento, o que mostra a gravidade da situação.

Todos os participantes da pesquisa possuem características de sofrimento, como mauhumor e tristeza, além de sintomas físicos como dor de cabeça, problemas de estômago e alterações do sono. E as principais reclamações destes estudantes foram quanto à falta de tempo e a necessidade de mudança na grade curricular. Estes problemas foram abordados em falas de alunos de todos os períodos, o que mostra a sua importância e necessidade de intervenção.

Como estratégias de lidar com esse sofrimento, pôde-se perceber mecanismos positivos, como a sublimação, descrita pela maioria dos alunos do Ciclo Clínico. Em contra partida, mecanismos negativos, como submissão às normas e regras do trabalho e o isolamento voluntário, foram identificados em sua maioria no Internato. Esse fato, aliado aos comentários relacionados a pressão excessiva realizados por estes estudantes do $9^{\circ}$ ao $12^{\circ}$ período, faz pensar que esta parte da faculdade seja a de maior sofrimento.

Ressalta-se a importância de refletir sobre a forma que os acadêmicos lidam com sua formação e pensar em estratégias para atenuar as vivências na universidade que podem levar ao sofrimento.

\section{REFERÊNCIAS}

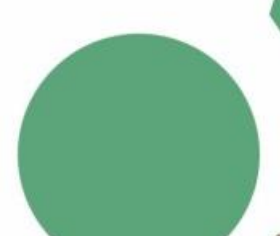

Anchieta, V. C., Galinkin, A. L., Mendes, A. M. B., \& Neiva, E. R. (2011). Trabalho e riscos de adoecimento: um estudo entre policiais civis. Psicologia: Teoria e Pesquisa, 27(2), 199208.

Andrade, J. B. C. D., Sampaio, J. J. C., Farias, L. M. D., Melo, L. D. P., Sousa, D. P. D., Mendonça, A. L. B. D., ... \& Cidrão, I. S. M. (2014). Contexto de formação e sofrimento psíquico de estudantes de medicina. Rev. bras. educ. med, 38(2), 231-242. Recuperado de 
http://www.scielo.br/scielo.php?pid=S010055022014000200010\&script=sci_abstract\&t1 $\underline{\mathrm{ng}}=\mathrm{pt}$

Benevides-Pereira, A. M. T., \& Gonçalves, M. B. (2009). Transtornos emocionais e a formação em Medicina: um estudo longitudinal. Rev bras educ med, 33(1), 10-23. Recuperado de: https://www.researchgate.net/profile/Ana_Benevides-

Pereira/publication/230853655_BenevidesPereira_Goncalves/links/09e4150566595c4bb3 000000.pdf

Costa, E. F.O., Santana, Y. S., de Abreu Santos, A. T. R., Martins, L. A. N., de Melo, E. V., \& de Andrade, T. M. (2012). Sintomas depressivos entre internos de medicina em uma universidade pública brasileira. Revista da Associação Médica Brasileira, 58(1), 53-59. Recuperado de: https://www.sciencedirect.com/science/article/pii/S0104423012704694

Dejours, C. (1992). A Loucura do Trabalho: Estudo de Psicopatologia do Trabalho. (5 a ed.) São Paulo: Cortez Editora.

Dejours, C. (1993). Uma nova visão do sofrimento humano nas organizações. O indivíduo na organização: dimensões esquecidas. São Paulo: Atlas.

Dejours, C., Abdoucheli, E., Jayet, C., \& Betiol, M. I. S. (1994). Psicodinâmica do trabalho: contribuições da escola dejouriana à análise da relação prazer, sofrimento e trabalho. $\left(1^{\mathrm{a}}\right.$ ed.). São Paulo: Atlas.

Dejours, C. (1999). A banalização da injustiça social. (6ª ed.). Rio de Janeiro: FGV Editora.

Dyniewicz, A. M. (2009). Metodologia da pesquisa em saúde para iniciantes. (2a ed.). São Caetano do Sul: Difusão Editora.

Facas, E. P. (2013). Protocolo de avaliação dos riscos psicossociais no trabalho-contribuições da psicodinâmica do trabalho (Doctoral dissertation, Tese de doutorado do Instituto de Psicologia da Universidade de Brasília-DF). Recuperado de: http://nucleotrabalho.com.br/wp-content/uploads/2018/12/1-2013_EmilioPeresFacas.pdf

Fiorotti, K. P., Rossoni, R. R., Borges, L. H., \& Miranda, A. E. (2010). Transtornos mentais comuns entre os estudantes do curso de medicina: prevalência e fatores associados. J Bras Psiquiatr, 59(1), 17-23. Recuperado de: http://www.scielo.br/pdf/jbpsiq/v59n1/v59n1a03

Girardi, J. F., \& Borges, L. M. (2017). Dimensões do sofrimento psíquico em estudantes universitários estrangeiros. Psico, 48(4), 256-263. Recuperado de: https://dialnet.unirioja.es/servlet/articulo?codigo $=6247870$

Mendes, A. M. (2007) Psicodinâmica do Trabalho: Teoria, método e pesquisas. São Paulo: Casa do Psicólogo.

Milanesi, K., Collet, N., Viera, C. S., \& Oliveira, B. R. G. (2008). Sofrimento psíquico em Dejours. Seminário Nacional: Estado e Políticas Sociais no Brasil. Cascavel: Edunioeste. Recuperado

de: php.unioeste.br/projetos/gpps/midia/seminario1/trabalhos/Saude/eixo2/68karinamilanesi. pdf 
Millan, L. R. (1999). Universo Psicológico Do Futuro Medico, O. São Paulo: Casa do Psicólogo.

Macêdo, K. B. (2015) O diálogo que transforma: a clínica psicodinâmica do trabalho. Goiânia: Ed. da PUC Goiás.

Pereira, M. A. (2014). O sofrimento psíquico na formação médica: percepções e enfrentamento do estresse por acadêmicos do curso de Medicina (Tese de doutorado da Universidade Federal de Goiás-GO). Recuperado de: https://repositorio.bc.ufg.br/tede/bitstream/tede/4381/5/Tese\%20\%20Maria\%20Am\%c3 \%a9lia\%20Dias\%20Pereira\%20-\%202014.pdf

Pereira, M. A. D. (2014). Sofrimento Psíquico: Percepção dos estudantes de medicina e a forma como lidam com a situação. CIAIQ2014, 3.

Ribeiro, M. D. G. S. (2014). Sofrimento psíquico entre estudantes de medicina da UFMG: uma contribuição da Assessoria de Escuta Acadêmica. (Dissertação de mestrado da Faculdade de Medicina da Universidade Federal de Minas Gerais - UFMG - MG). Recuperado de: http://www.bibliotecadigital.ufmg.br/dspace/bitstream/handle/1843/BUOS9UKRAM/diss erta_o_final_sem_artigo_04_12_14.pdf?sequence=1

Ribeiro, M. D. G. S., Cunha, C. D. F., \& Alvim, C. G. (2016). Trancamentos de Matrícula no Curso de Medicina da UFMG: Sintomas de Sofrimento Psíquico. Rev. bras. educ. méd, 40(4), 583-590. Recuperado de: http://www.scielo.br/scielo.php?pid=S0100$\underline{55022016000400583 \& \text { script }=\text { sci_abstract\&tlng }=\text { pt }}$

Zonta, R., Robles, A. C. C., \& Grosseman, S. (2006). Estratégias de enfrentamento do estresse desenvolvidas por estudantes de medicina da Universidade Federal de Santa Catarina. Rev bras educ méd, 30(3), 147-53. Recuperado de: http://www.scielo.br/pdf/\%0D/rbem/v30n3/04.pdf 